\title{
Invasive vs. Non-Invasive Methods in Estimating Slope Stability, with Application in the Copou Area, Iaşi, Romania
}

\author{
F. Pascariu, C. Negru*, M.R. Şaramet and C. Chelariu \\ "Alexandru Ioan Cuza" University of Iaşi, Faculty of Geography and Geology, Department of Geology, Iaşi, Romania
}

\begin{abstract}
Slope stability analysis represents nowadays a constant pursuit, being applied in various domains, such as geological and geomorphological studies, civil engineering or urban expansion. In this paper, two different methods were employed in order to establish the stability of the Copou Hill, Iaşi, Romania, and the results were compared. The first, non-invasive, method involves obtaining a landslide risk map by identifying the factors that induce the slope failure and overlaying the obtained maps. The second one, invasive, implies computing a safety factor using the infinite slope method, employing well data from this area and ranging the thickness of the water column. This comparison was made in order to improve the non-invasive method, so as to apply it in areas where there is no geological information. The resulting landslide risk map shows values of the average coefficient $K_{m}$ ranging between 0.21 and 0.63 , implying a medium to high failure probability for the studied slope. On the other hand, the infinite slope method indicates a safety factor with values between 0.91 and 1.49 , at a complete flooding of the land-sliding lithological column, with a single exception with much lower value. These values are below the admissible factor, suggesting failure with a medium to high probability. Comparing these two methods, significant similarities between the landslide risk map results and the computed safety factors can be observed. For further testing of the first method, similar studies should also be made in other areas.
\end{abstract}

DOI: 10.12693/APhysPolA.128.B-193

PACS: 91.30.pd, 91.62.Ty, 92.40.Ha

\section{Introduction}

Slope failure represents a phenomenon that manifests more and more violently, having a major play in the landscape dynamics. It can produce significant material damages, as well as life lost. Therefore, their study represents an important aspect in various researching branches such as geology, geomorphology, geotechnical projects, civil engineering and urbanism.

This paper aims to compare a non-invasive method, for establishing the landslide risk of a certain slope, to an invasive method, that computes the safety factor of the same slope. The comparison was made in order to improve the non-invasive method to be able to employ it in areas where there are no well data.

\section{Study area}

The studied area is located in the northern part of Iaşi municipality (Romania), having as geographical coordinates $\mathrm{N} 47^{\circ} 10^{\prime}$ and $\mathrm{E} 27^{\circ} 35^{\prime}$. Copou is one of the seven hills, on which Iaşi city is extended. This area is part of the Moldavian Plane, a sub-unit of the Moldavian Plateau. Among the slopes that compose the Copou Hill, only two were studied, Copou East and Ursulea, respectively (Fig. 1). The aspect of the analysed slopes is a deluvial one [1], exhibiting multiple scars from prior landslides.

From a geological point of view, Copou Hill belongs to the Moldavian Platform, the south-western part of the East-European Platform [2]. The deposits that outcrop

*corresponding author; e-mail: cristina.negru88@gmail.com

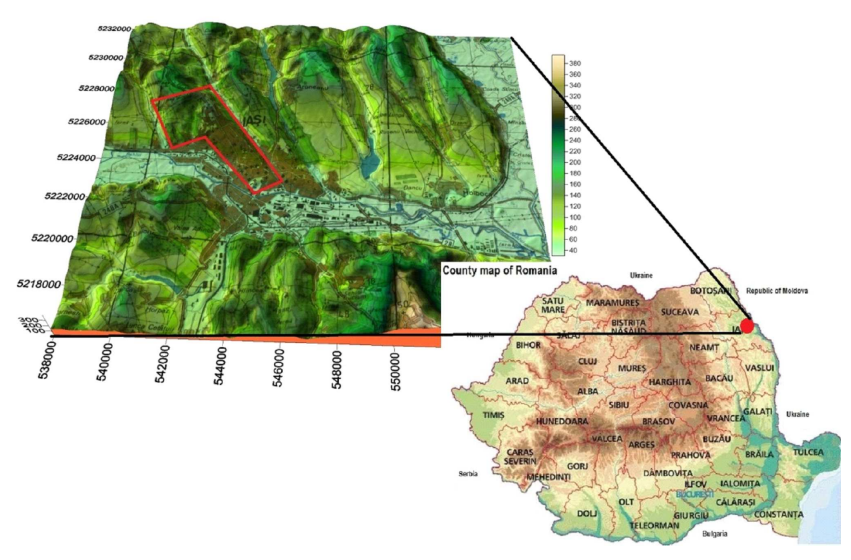

Fig. 1. The localisation of the study area. The red polygone borders the Copou East and Ursulea slopes.

on the studied slopes are of Quaternary age, with Sarmatian deposits (Middle Miocene) at their base. The dominant lithological deposits are silty clays with numerous sandy lens, sands and marly clays.

Choosing this study area was based on the fact that most factors that may trigger the landslide can be identified here: lithology, slope, ground water close to the surface, the area hydrogeology, the geological positioning on the eastern flank of the slope, numerous buildings that exert significant terrain overload, etc. Copou East and Ursulea slopes underwent multiple remodeling with time, the first mentions of such slides being made by [3]. The author notes some landslides that occurred in the spring of 1942 , pointing out that they have taken place in the past, too, and the main triggering factor was the water. 


\section{Methods}

In this paper, two methods were compared in order to estimate the field stability in the area of the Copou East and Ursulea slopes.

The first method, non-invasive, is based on the employment of the guidelines described in GT 019-98 [4], a technical guide used in Romania for landslide risk map elaboration. It implies estimating the landslide potential of a slope by analyzing 8 factors considered determinant for the massif stability, and applying an equation. These 8 analyzed factors are described in Table I.

The influence factors proposed in GT 019-98 [4] and the choosing criteria for their value.

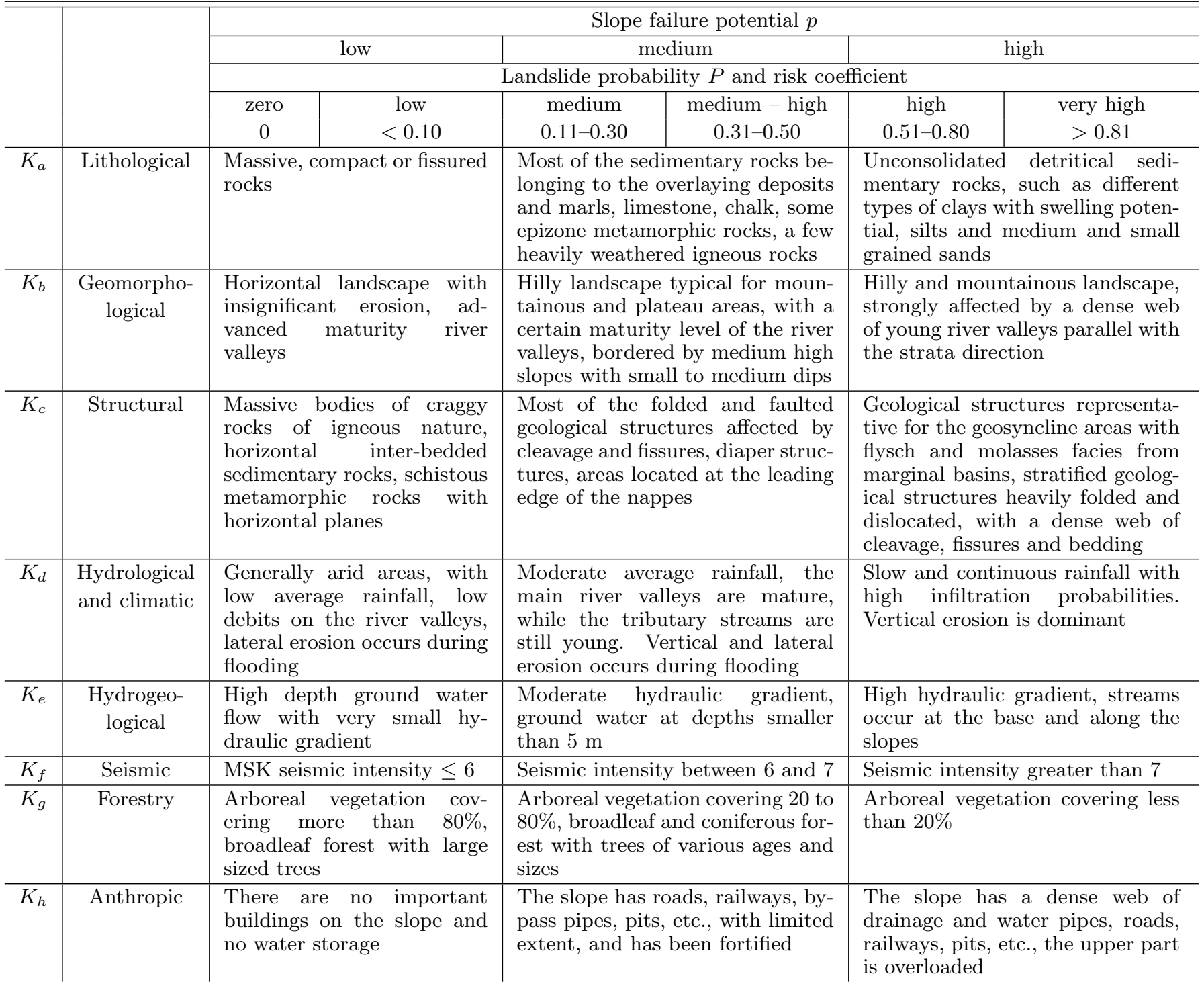

Landslide influence maps are made for each analyzed factor, then these maps are overlaid. A mean factor $\left(K_{m}\right)$ is computed according to

$$
K_{m}=\sqrt{\frac{K_{a} K_{b}}{6}\left(K_{c}+K_{d}+K_{e}+K_{f}+K_{g}+K_{h}\right)} .
$$

and then plotted resulting a landslide risk map for the studied slope. ArcGIS software was employed as the work tool. A more detailed explanation in choosing each factor values can be found in [5].

The second method, the infinite slope method, is named invasive because it employs date obtained from geotechnical wells. Choosing this method was based on the geometry of the studied slopes, which have a deluvial aspect, thus considering a plane sliding surface. 
The infinite slope method interprets the slope as a (infinite length) prism, with a plane sliding surface, being characterized by a ground water flow direction in concordance with the slope dipping direction [6]. The factor of safety must meet the following condition: $F_{s}$ effective $\geq F_{s}$ admissible, where:

- $F_{s}$ effective represents the slope effective safety coefficient, estimated using the chosen computation method;

- $F_{s}$ admissible represent the safety coefficient established by standards or good practice, having a more or less conventional nature.

In this paper, the value of $F_{s}$ admissible was chosen to be $1.5[7,8]$.

The utilized computation formula is

$$
\begin{aligned}
& F_{s}=\frac{\tau_{f}}{\tau}=\frac{\sigma \tan \Phi+c}{\tau}= \\
& \quad \frac{\left[\gamma\left(H-H_{w}\right)+\gamma^{\prime} H_{w}\right] \cos ^{2} \beta \tan \Phi+c}{\left[\gamma\left(H-H_{w}\right)+\gamma_{s r} H_{w}\right] \cos \beta \sin \beta},
\end{aligned}
$$

where $\tau_{f}$ — shearing resistance at failure, $\tau$ - shear strength (stress), $\sigma$ - normal stress, $\gamma$ - the rock specific weight, $\gamma^{\prime}$ - the submerged unit weight, $\gamma_{s r}$ - the saturated unit weight, $H$ - the total thickness of the column above the failure surface, $H_{w}$ - the thickness of the water column, $\Phi$ - the internal friction angle, $c$ cohesion, $\beta$ - the slope of the terrain.

The computation was made considering a complete flooding of the lithological columns $\left(H=H_{w}\right)$.

\section{Results and discussions}

Using the guidelines proposed in [4], the non-invasive method, the values of the landslide influence factors were established for the analyzed slopes. These values, as well as their choosing motivation, were summarized in Table II.

Influence maps were made for each landslide influence factor, and then these maps were overlaid using Eq. (1). Finally, the landslide risk map resulting for Copou East and Ursulea slopes is plotted in Fig. 2.

The results obtained using the infinite slope method, the invasive method, were summarized in Fig. 3. The computations were made using some of the data cited in [9]. Generally, the lithological types that show a safety factor lower that 1.5 are the sand films bearing clays and the marly clay. These rocks represent potential displacement surfaces of the sliding mass. The main cause for the existence a safety factor smaller than 1 is the exceedingly steep slope, relative to the other studied well sites $\left(23^{\circ}\right)$, and for a safety factor greater than 1.7 is a very small slope angle; these are exceptions for the studied slopes and were neglected.

The comparison between these two methods was possible by classifying the obtained results in terms of the landslide probability they indicate. Thus, using the data
TABLE II

The values of the landslide influence factors for the stud-

\begin{tabular}{|c|c|c|}
\hline Factor & Value & Motivation \\
\hline$K_{a}$ & 0.9 & $\begin{array}{l}\text { Miocene to Quaternary detritical } \\
\text { sedimentary rocks }\end{array}$ \\
\hline$K_{b}$ & $0.1-0.6$ & slopes between $0-30^{\circ}$ \\
\hline$K_{c}$ & 0.6 & geosyncline area \\
\hline$K_{d}$ & 0.5 & average annual rainfall of $600 \mathrm{~mm}$ \\
\hline$K_{e}$ & 0.8 & $\begin{array}{l}\text { areas with slope springs and pro- } \\
\text { ductive aquifers }\end{array}$ \\
\hline$K_{f}$ & 0.8 & msk seismic intensity equal to 8 \\
\hline \multirow{2}{*}{$K_{g}$} & 0.3 & areas with broadleaves forest \\
\hline & 0.9 & areas without arboreal vegetation \\
\hline \multirow{5}{*}{$K_{h}$} & 0.1 & areas without buildings \\
\hline & 0.3 & areas with isolated households \\
\hline & 0.5 & earth roads \\
\hline & 0.7 & national roads \\
\hline & 0.9 & areas with large buildings \\
\hline
\end{tabular}
ied slopes, and their choosing motivation.

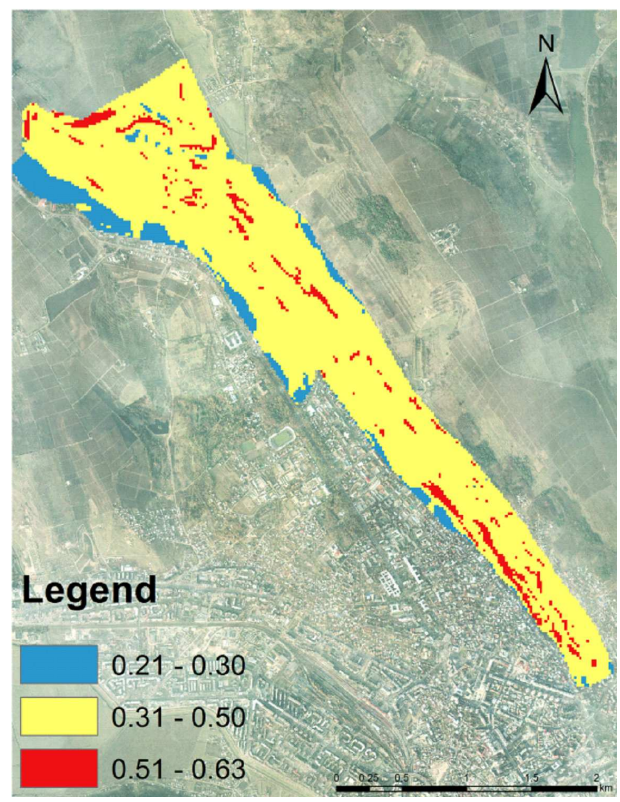

Fig. 2. The landslide risk map for Copou East and Ursulea slopes. The blue areas indicate a medium landslide probability, the yellow area indicates a medium-high probability, and the red areas indicate a high probability.

from Table I [4] and the landslide risk map from Fig. 2, the landslide probabilities for Copou East and Ursulea slopes are categorized in heading of Table I. Landslide probability is medium for $K_{m}=0.21 \div 0.3$, medium-high for $K_{m}=0.31 \div 0.5$ and high for $K_{m}=0.51 \div 0.63$.

The final estimation of the landslide probability based on the results obtained using the invasive method was made in relation to the literature data [7]. Based on these data, the landslide probabilities indicated by the 


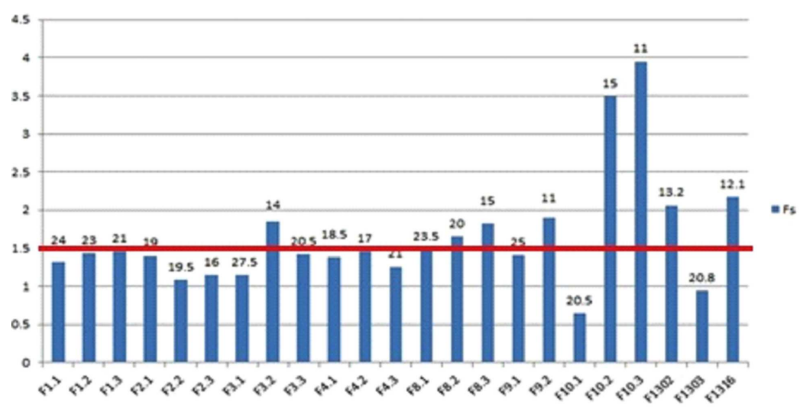

Fig. 3. Histogram showing the values of the safety factor for each analyzed well, computed using the infinite slope stability method, at complete flooding of the lithological column. The red line marks the admissible $F_{s}$ (1.5).

infinite slope method are summarized in Table III.

TABLE III

The summarized landslide probability results using the invasive method.

\begin{tabular}{c|c|l}
\hline \hline Safety & Probability & Description \\
\hline$\leq 1$ & very high & areas with active landslides \\
high & $\begin{array}{l}\text { areas with temporary stable } \\
\text { landslides and high reactivation } \\
\text { potential } \\
\text { areas with stabilized land- } \\
\text { slides and medium reactivation } \\
\text { potential } \\
\text { relatively stable areas }\end{array}$ \\
& medium
\end{tabular}

Non-invasive and invasive methods indicate similar landslide probabilities, medium, medium-high and high probabilities in case of the non-invasive method, and medium and high probabilities in case of the invasive method.

\section{Conclusion}

The results obtained using the infinite slope method, indicate medium and high landslide probabilities in Copou-Ursulea area. The rocks most affected by the landslides are the clays with sand lens and the marly clay.
The non-invasive method indicates, based on the landslide risk map, medium, medium-high, and high landslide probabilities.

Comparing these two methods, a good correlation between the results can be observed. One can conclude that the non-invasive method could also be used in areas where there are no well data. For further testing of this method, its comparison with other computation methods for various other perimeters is recommended.

\section{References}

[1] V. Băcăuanu, Scientific Annals of the "Al. I. Cuza" University from Iaşi (new series), Section II, Geography, Vol. XVI, Iaşi 1970, p. 143 (in Romanian).

[2] L. Ionesi, Bica Ionesi, Al. Lungu, V. Roşca, V. Ionesi, Medium and Upper Sarmatian from the Moldavian Platform, Romanian Academy Pub., Iaşi 2005, p. 1 (in Romanian).

[3] N. Macarovici, "V. Adamachi" Sci. Mag. XXVIII, 185 (1942) (in Romanian).

[4] GT 019-98, Guide for Generating the Slope' Landslide Risk Maps in order to Ensure the Constructions' Stability, Developer: I.S.P.I.F. Bucharest (in Romanian).

[5] Project no. 114/2011, The Elaboration of the Landslide Risk Maps for the Areas of Neamt County Exposed to This Phenomenon, S.C. Topoprest S.R.L., Piatra Neamţ (in Romanian).

[6] T. Silion, V. Muşat, L. Olaru, Engineering Geology, "Al. I. Cuza" University, Iaşi 1984, p. 134 (in Romanian).

[7] A. Stanciu, L. Lungu, Foundations. The Soils' Physics and Mechanics, Technical Pub., Bucharest 2006 (in Romanian).

[8] C.J. Van Westen, Deterministic Landslide Hazard Zonation, Department of Earth Systems Analysis, International Institute for Geo-Information Science and Earth Observation (ITC), AA Enschede, The Netherlands.

[9] D. Purice, Ph.D. Thesis, "Al. I. Cuza" University from Iaşi, 2013 (in Romanian). 